\title{
Heterologous ovum penetration by human spermatozoa
}

\author{
J. P. P. Tyler*, J. P. Pryor $†$ and W. P. Collins \\ Departments of Obstetrics and Gynaecology, and $\dagger$ Urology, King's College Hospital Medical \\ School, Denmark Hill, London, SE5 8RX, U.K.
}

\begin{abstract}
Summary. An evaluation of a method utilizing zona-free hamster ova to test the fertility of human spermatozoa has shown that (i) the induction of superovulation in immature animals provides the most convenient method of obtaining mature ova for study; (ii) motile spermatozoa are best prepared by the technique of layering; (iii) an $18 \mathrm{~h}$ incubation at $37^{\circ} \mathrm{C}$ (which is associated with capacitation) in an atmosphere of air ( $\mathrm{pH}$ of medium 8.2) is preferable to one of $5 \% \mathrm{CO}_{2}$ ( $\mathrm{pH}$ of medium 7.2); (iv) the incubation and insemination densities of spermatozoa should be $>1 \times 10^{6}$ and $<10$ $\times 10^{6} / \mathrm{ml}$; (v) spermatozoa do not remain motile, or capable of binding to or penetrating ova, after about $30 \mathrm{~h}$ in culture; and (vi) intra- and inter-assay variations are acceptable. The spermatozoa from 15 healthy men of proven fertility and 15 subfertile patients with normal spermiograms were evaluated for their ability to bind to and penetrate zona-free hamster ova. Of the 476 ova inseminated with spermatozoa from the fertile men $>5$ spermatozoa/ovum consistently bound to the vitelline membrane and 284 ova $(59.7 \%)$ had swollen sperm heads or pronuclei (still with tails attached) in their ooplasm. The range of individual penetration rates was $23.5-88.9 \%$. Of the 586 ova tested with spermatozoa from the infertile subjects only $11(1.9 \%)$ showed any evidence of penetration (range of individual penetration rates $0-8.7 \%)$ and binding to the vitelline membrane was poor $(0$ or $<5$ spermatozoa/ ovum). Spermatozoa from a further 9 infertile men who had abnormal spermiograms also gave poor penetration rates $(4 / 300$ ova, $1 \cdot 3 \%)$. It is concluded that this bioassay has a useful role as an additional test to the classic spermiogram, but that its routine use is best reserved for selected cases of unexplained infertility.
\end{abstract}

\section{Introduction}

The initial investigation of a male partner in an infertile marriage involves assessment of his semen. Unfortunately, the use of spermiograms to assess the potential of a male to fertilize a female is complicated by many factors. For example, the results obtained are dependent upon the frequency of ejaculation, the general health of the subject and age of the sample at the time of analysis. In addition, there is considerable inter-man variation in the results obtained under well-defined conditions. Notwithstanding these limitations, there have been reports in which an attempt has been made to relate fertility to the parameters of sperm density (Van Zyl, Menkveld, Retif \& Niekerk, 1976), progressive motility (Eliasson, 1976) and the percentage of morphologically normal spermatozoa. The main conclusion from these studies is that azoospermia is the only reliable index of infertility from a spermiogram. Although this condition is easily recognized, it is the exception, and changes in semen quality during therapy are difficult

* Present address: Department of Obstetrics and Gynaecology, The Parramatta Hospitals/Westmead Centre, Westmead, New South Wales 2145, Australia. 
to interpret with existing methods. To date, the only dynamic test with a high correlation in relation to fertility is the mucus penetration test accurding to the method of Kremer (Ulstein \& Fjallbrant, 1976), but this procedure requires a regular supply of mid-cycle cervical mucus and is still not an index of the fertilizing capacity of a semen sample.

The fertilization of human oocytes in vitro has proved technically possible (Steptoe \& Edwards, 1978; Lopata, Brown, Leeton, McTalbot \& Wood, 1978), but presents too many practical problems for use as a clinical test. Another approach has been the use of ova from laboratory animals because if the zona pellucida is removed heterologous spermatozoa may penetrate the cytoplasm (Hanada \& Chang, 1972). Human spermatozoa are capable of penetrating zona-free hamster oocytes after an in-vitro incubation probably associated with capacitation (Yanagimachi, Yanagimachi \& Rogers, 1976), and a relationship may occur between this in-vitro penetration and infertility (Barros, Gonzalez, Herrera \& Bustos-Obregon, 1978, 1979; Rogers et al., 1979; Hall, Sloane \& Hammond, 1980; Overstreet, Yanagimachi, Katz, Hajashi \& Hanson, 1980). Theoretically, such a dynamic test will provide a better index of potential fertility than routine semen analysis because several functional properties of spermatozoa are examined which are related to fertilization (i.e. motility, viability, capacitation and penetration).

The aims of this study were twofold. Firstly, to evaluate the variables when establishing a heterologous gamete penetration test for use in a routine laboratory and, secondly, to examine the usefulness of this test by its application to semen from (i) healthy volunteers of proven fertility, (ii) men with normal spermiograms and a healthy potentially fertile wife, but an infertile marriage of more than 1 year, and (iii) patients with abnormal spermiograms.

\section{Materials and Methods}

Semen samples were obtained from husbands of couples attending a subfertility clinic, and from men known to be of proven fertility (including AID donors). Group 1 comprised 15 subjects who had normal spermiograms (i.e. semen volume 2-6 ml; sperm density $20-250 \times 10^{6} / \mathrm{ml} ;>40 \%$ motile spermatozoa; $>60 \%$ normal morphological types) and whose wives had conceived within the last 2 years. Similarly, the 15 subjects who comprised Group 2 had spermiograms with values within the normal range, but were partners of women who had no known gynaecological or endocrinological cause for infertility ( $>1$ year). Nine other men (Group 3) from infertile marriages and with an abnormal spermiogram (sperm density $<20 \times 10^{6} / \mathrm{ml}$ and $/$ or $<40 \%$ motile forms) also had their semen tested for comparison.

The culture medium (BWW) used throughout the experiments was that of Biggers, Whitten \& Whittingham (1971) supplemented with $20 \mathrm{mM}$-Hepes and $3 \mathrm{mg} \mathrm{HSA} / \mathrm{ml}$. Medium was sterilized by Millipore filtration and aseptic conditions were maintained throughout the sperm preparation, recovery of ova and insemination. Spermatozoa were prepared by one of two methods.

Centrifugation and resuspension. A small volume $(0.5 \mathrm{ml})$ of semen was added to $5 \mathrm{ml}$ BWW, mixed and centrifuged at $600 \mathrm{~g}$ for $6 \mathrm{~min}$. The supernatant was removed and the spermatozoa resuspended in $5 \mathrm{ml} \mathrm{BWW}$. Centrifuged pellets were washed twice more before final resuspension in $1 \mathrm{ml}$ medium. After determining the sperm density, samples were diluted to give a final concentration for preincubation of $1-10 \times 10^{6}$ spermatozoa $/ \mathrm{ml}$. Diluted samples $(0.5 \mathrm{ml})$ were left overnight (approx. $18 \mathrm{~h}$ ) at $37^{\circ} \mathrm{C}$ in small tightly stoppered sterile containers.

Active dilution (layering). Semen $(0.5 \mathrm{ml})$ was carefully pipetted under $5 \mathrm{ml} \mathrm{BWW}$ to form two distinct layers and left in the dark at $37^{\circ} \mathrm{C}$ for $1-1.5 \mathrm{~h}$. Motile spermatozoa were concentrated from the supernatant by centrifugation, and washed as before in two changes of BWW before diluting and preincubation as above.

The heterologous gamete penetration test utilizing zona-free hamster ova has been described previously (Yanagimachi et al., 1976; Rogers et al., 1979). Briefly, adult and immature 
(25-30-day-old) hamsters (Mesocricetus auratus) were induced to superovulate and the ova were collected, stripped of their cumulus and zona and after three washes in BWW transferred to $150 \mu \mathrm{l}$ droplets of preincubated sperm suspensions under paraffin oil. Insemination droplets were incubated at $37^{\circ} \mathrm{C}$ in an atmosphere of $5 \% \mathrm{CO}_{2}$ in air and $100 \%$ humidity. After $2.5 \mathrm{~h}$ ova were removed from the droplets and washed in BWW. Only spermatozoa bound to the vitelline membrane survived this procedure. Using Nomarski optics and a magnification of 400, the number of attached spermatozoa per oocyte was scored as zero, $<5$, or $>5$. A swelling sperm head/heads, or male pronuclei connected to a visible sperm tail was considered evidence of positive penetration of an ovum.

\section{Results}

\section{Collection of oocytes}

Only those oocytes with a visible first polar body were used in these studies because penetration rates differ in oocytes at meiotic stages before metaphase 2 (Iwamatsu \& Chang, 1972). Ova can be collected from the oviducts after induction of superovulation, or from culture in vitro of immature oocytes recovered from antral follicles. However, the combination of poor recovery of viable oocytes and the low rate of polar body formation after culture in $\mathrm{BWW}$ exclude this method for routine use (see Table 1). After induction of superovulation high yields of ova with visible polar bodies were obtained from immature and adult animals (about 40/animal).

When the penetration rates of 5 different semen samples were compared using ova from immature and adult animals induced to superovulate there was no statistically significant difference between the results. Therefore for all further experiments immature animals were used.

Table 1. The recovery of mature oocytes (with visible first polar body) by induction of superovulation or spontaneous maturation in vitro from immature and adult hamsters

\begin{tabular}{cllccccc}
\hline \multirow{2}{*}{$\begin{array}{c}\text { Source of } \\
\text { oocytes }\end{array}$} & \multicolumn{2}{c}{ Hamsters } & & \multicolumn{4}{c}{ No. of oocytes } \\
\cline { 2 - 3 } & Status & No. & Recovered & $\begin{array}{c}\text { Without signs of } \\
\text { degeneration } \\
(\%)\end{array}$ & $\begin{array}{c}\text { With first } \\
\text { polar body } \\
(\%)^{*}\end{array}$ & $\begin{array}{c}\text { Mean no. of } \\
\text { usable oocytes/ } \\
\text { animal }\end{array}$ \\
\hline Superovulation & Immature & 40 & 1702 & $1594(93 \cdot 7)$ & $1594(100)$ & 39.9 \\
& Adult & 39 & 1604 & $1591(99.2)$ & $1591(100)$ & 40.8 \\
\hline Antral follicles & Immature & 12 & 145 & $130(89.7)$ & $56(43.1)$ & 4.7 \\
& Adult & 13 & 128 & $112(87.5)$ & $40(35.7)$ & 3.1 \\
\hline
\end{tabular}

* Of oocytes without signs of degeneration.

\section{Preparation of spermatozoa}

Centrifugation and resuspension. Preliminary experiments had demonstrated that three washes of spermatozoa were necessary (after overnight incubation) to maintain motility values similar to those of the original sample.

When 5 different volumes $(0.1,0.3,0.5,0.7$ and $1.0 \mathrm{ml})$ from each of 6 semen samples were prepared the overall geometric mean recovery of spermatozoa was $68.4 \%$ (limits of 1 standard deviation $52 \cdot 6-89.0 \%$ ). The correlation coefficient between the volume taken and percentage recovery was poor $(r=0.66 ; n=30)$, and recoveries were lowest when only $0.1 \mathrm{ml}$ semen was taken. However, if at least $0.3 \mathrm{ml}$ was used for the preparation then recoveries were generally $>50 \%$ and independent of volume or count taken $(r=0.44 ; n=25)$. Therefore for all further evaluations $0.5 \mathrm{ml}$ semen was used. 
When 40 other samples (range of counts 5.0-215.5 $\times 10^{6} / \mathrm{ml}$ : geometric mean $26.9 \times$ $10^{6} / \mathrm{ml}$ ) were evaluated there was a good correlation between the initial and the recovered count $(r=0.92)$ and the geometric mean recovery was $52.7 \%$ (range $15.8-100 \%)$. Furthermore, there was no significant difference between the motility of spermatozoa in samples before or after concentration although the mean difference was reduced by $13.6 \%$ after preparation (geometric mean recovery of motile spermatozoa $39.5 \%$ with a range of $4.6-135 \%$ ).

Active dilution (layering). Since it was practicable, $0.5 \mathrm{ml}$ semen was taken for these studies. Preliminary experiments demonstrated that spermatozoa left for $18 \mathrm{~h}$ in aspirated medium became immotile and two washes with $5 \mathrm{ml} \mathrm{BWW}$ were necessary to retain motility.

When 32 samples (range of counts 10.0-158.0 $\times 10^{6} / \mathrm{ml}$; range of motility 10-75\%) were individually layered the geometric mean percentage recovery was $13.8 \%$. There was no relationship between the original motility of the sample and the percentage recovery $(r=0.28)$ but the motility of the recovered spermatozoa was always in excess of $90 \%$. Furthermore, there was no relationship between the number of motile spermatozoa taken for layering and the recovered count, if it was assumed to be $100 \%$ motile $(r=0.47)$.

Recovery of motile spermatozoa from semen samples with low counts $\left(<10 \times 10^{6} / \mathrm{ml}\right)$, and/or $<20 \%$ motility (i.e. Group 3 subjects) was generally poor, even after concentration by centrifugation, so for these samples centrifugation and resuspension was used. However, spermatozoa from men in Groups 1 and 2 and all other samples for further experiments were prepared by layering.

Conditions for preincubation. The effects of preincubating spermatozoa for approximately 18 $\mathrm{h}$ in an air or $5 \% \mathrm{CO}_{2}$ atmosphere at $37^{\circ} \mathrm{C}$ are shown in Table 2 . The motility of samples left in air $\left(\mathrm{pH}\right.$ of the medium 8.2 ) was always $>80 \%$ but was slightly less in $\mathrm{CO}_{2}$-incubated samples ( $\mathrm{pH}$ of medium 7.2). Binding to the vitelline membrane and penetration of the cytoplasm was consistently poorer in $\mathrm{CO}_{2}$-incubated samples. Four other samples of prepared spermatozoa left at room temperature $\left(22^{\circ} \mathrm{C}\right)$ also maintained their motility over $24 \mathrm{~h}$ and penetrated zona-free ova, although no comparative study was undertaken. For all further experiments spermatozoa were preincubated in air at $37^{\circ} \mathrm{C}$.

Table 2. The effect on attachment to, and penetration of, zona-free hamster ova by human spermatozoa after preincubation for $18 \mathrm{~h}$ in air or $5 \% \mathrm{CO}_{2}$

\begin{tabular}{|c|c|c|c|c|c|c|c|c|c|}
\hline \multirow[b]{3}{*}{$\begin{array}{c}\text { Sample } \\
\text { no. }\end{array}$} & & & \multirow{3}{*}{$\begin{array}{c}\text { Test } \\
\text { count } \\
\times 10^{6} / \mathrm{ml}\end{array}$} & \multicolumn{6}{|c|}{ Preincubation in } \\
\hline & \multicolumn{2}{|c|}{ Original } & & \multicolumn{3}{|c|}{$5 \% \mathrm{CO}_{2}$} & \multicolumn{3}{|c|}{ Air } \\
\hline & $\begin{array}{c}\text { Count } \\
\times 10^{6} / \mathrm{ml}\end{array}$ & $\begin{array}{l}\text { Motility } \\
(\%)\end{array}$ & & $\begin{array}{l}\text { Motility } \\
(\%)\end{array}$ & Attachment* & $\underset{\text { tration }}{\text { Pene- }}$ & $\begin{array}{l}\text { Motility } \\
(\%)\end{array}$ & Attachment* & $\begin{array}{c}\text { Pene- } \\
\text { tration }\end{array}$ \\
\hline 1 & 17.0 & 50 & 1.0 & 50 & $0 /+$ & $9 / 30(30)$ & $>80$ & ++ & $26 / 32(81)$ \\
\hline 2 & 10.0 & 50 & 1.2 & 50 & $0 /+$ & $0 / 31(0)$ & $>80$ & $+1++$ & $7 / 25(28)$ \\
\hline 3 & 14.0 & 60 & 2.0 & 70 & $0 /+$ & $5 / 30(17)$ & $>80$ & ++ & $18 / 32(56)$ \\
\hline 4 & 17.0 & 40 & 2.9 & 60 & $0 /+$ & $0 / 29(0)$ & $>80$ & $+1++$ & $2 / 43(5)$ \\
\hline 5 & 72.5 & 60 & 3.4 & 60 & $0 /+$ & $0 / 35(0)$ & $>80$ & ++ & $26 / 45(58)$ \\
\hline 6 & 89.0 & 80 & 4.0 & 70 & $0 /+$ & $2 / 37(5)$ & $>80$ & $0 /+$ & $6 / 36(17)$ \\
\hline 7 & 116.5 & 65 & 5.5 & 60 & $0 /+$ & $4 / 31$ (13) & $>80$ & ++ & $7 / 28(25)$ \\
\hline 8 & 70.5 & 80 & 6.2 & 80 & $0 \%+$ & $1 / 29$ (3) & $>80$ & ++ & $11 / 29(38)$ \\
\hline 9 & 44.0 & 70 & 7.7 & 50 & $0 /+$ & $0 / 22(0)$ & $>80$ & ++ & $15 / 30(50)$ \\
\hline
\end{tabular}

* 0 , no attachment;,$+ 1-5$ spermatozoa attached;,$++>5$ spermatozoa attached.

$\dagger$ No. of ova penetrated per total no. of ova $(\%)$.

Age of prepared spermatozoa. Preincubated spermatozoa left for a further $24 \mathrm{~h}$ before testing again with zona-free ova invariably had poor motility and sluggish progression. There was also a marked increase in the number of spermatozoa agglutinated to each other. Concomitant with these changes, the binding of spermatozoa to zona-free ova and the penetration rate decreased significantly as shown in Table 3. However, when semen samples left by patients between 09:00 
Table 3. The effect on sperm motility, binding to and penetration of zona-free hamster ova by human spermatozoa after preincubation in air for 18 or $42 \mathrm{~h}$ at $37^{\circ} \mathrm{C}$

\begin{tabular}{cccccccc}
\hline & \multicolumn{3}{c}{$18 \mathrm{~h}$} & & \multicolumn{2}{c}{$42 \mathrm{~h}$} \\
\cline { 2 - 3 } \cline { 7 - 8 } Sample & Motility & Attachment* & Penetration $\dagger$ & & Motility & Attachment* & Penetration $\dagger$ \\
\hline 1 & $>80$ & ++ & $12 / 58(21)$ & & $<10$ & $0 /+$ & $1 / 42(2)$ \\
2 & $>80$ & ++ & $12 / 59(20)$ & & $<10$ & 0 & $0 / 30(0)$ \\
3 & $>80$ & ++ & $30 / 41(73)$ & & 20 & $+/++$ & $3 / 35(9)$ \\
4 & 60 & + & $2 / 38(5)$ & & $<10$ & 0 & $0 / 36(0)$ \\
5 & $>80$ & ++ & $7 / 45(16)$ & & $<10$ & $0 /+$ & $0 / 32(0)$ \\
6 & $>80$ & ++ & $16 / 37(43)$ & & $<10$ & $0 /+$ & $2 / 39(5)$ \\
\hline
\end{tabular}

* 0 , no attachment;,$+ 1-5$ spermatozoa attached;,$++>5$ spermatozoa attached.

$\dagger$ No. of ova penetrated per total no. of ova (\%).

and 10:00 $\mathrm{h}$ (instead of 13:00-14:30 $\mathrm{h}$ as usually requested) were tested the following morning (i.e. $24 \mathrm{~h}$ preincubation) results comparable to those left for $18 \mathrm{~h}$ were obtained.

Effect of preincubation density. Eight sperm samples were serially diluted from their prepared density and preincubated for $18 \mathrm{~h}$. The changing penetration rate for each dilution of each sample is shown in Text-fig. 1. It is difficult to draw any firm conclusions from this experiment except to say that penetration rates appear to be unaffected by concentrations over the range 1-8 $\times 10^{6} / \mathrm{ml}$. However, at densities $<1 \times 10^{6} / \mathrm{ml}$ or $>10 \times 10^{6} / \mathrm{ml}$ penetration rates may decrease.

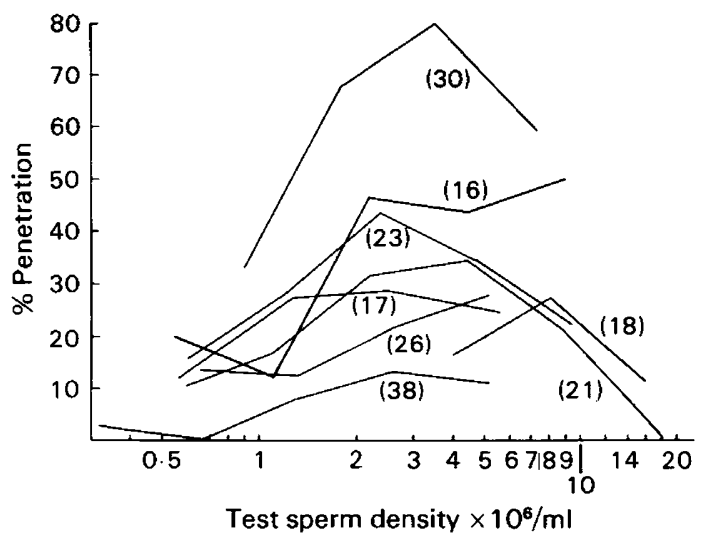

Text-fig. 1. The effect of preincubation and insemination density of human spermatozoa on penetration rate. The values in parentheses are the average no. of ova tested per dilution for each sample.

\section{Within-subject variation}

The variation in penetration rates between 6 different semen samples from 3 subjects is shown in Table 4. Subject $\mathrm{C}$ gave the most constant penetration rates (coefficient of variation 44.7\%) and in Subject A only one value was inconsistent (coefficient of variation 56.0\%). This could not be explained by a 'poor assay' because other samples in that assay gave good penetration results. Similarly, Subject B had 2 test values of 21.7 and $22.0 \%$ which were inconsistent with the other 4 samples tested (coefficient of variation $77.5 \%$ ).

For each sample from each subject, groups of approximately 10 ova were distributed to replicate sperm droplets under oil. The numbers were too low for meaningful statistical analysis, but for each sample, replicate droplets gave comparable results confirming good intra-assay variation. 
Table 4. Replicate penetration rates from 3 subjects

\begin{tabular}{|c|c|c|c|c|c|c|}
\hline \multirow[b]{2}{*}{ Sample } & \multicolumn{2}{|c|}{ Subject A } & \multicolumn{2}{|c|}{ Subject B } & \multicolumn{2}{|c|}{ Subject C } \\
\hline & $\begin{array}{l}\text { Count* } \\
\times 10^{6} / \mathrm{ml}\end{array}$ & Penetration $\dagger$ & $\begin{array}{l}\text { Count } \\
\times 10^{6} / \mathrm{ml}\end{array}$ & Penetration $\dagger$ & $\begin{array}{l}\text { Count* } \\
\times 10^{6} / \mathrm{ml}\end{array}$ & Penetration $\dagger$ \\
\hline 1 & $2 \cdot 6$ & $30 / 58 \quad(51.7)$ & 3.4 & $3 / 51 \quad(5.9)$ & 3.6 & $16 / 38 \quad(42 \cdot 1)$ \\
\hline 2 & $5 \cdot 9$ & $1 / 25 \quad(4 \cdot 0)$ & $2 \cdot 9$ & $7 / 76 \quad(9 \cdot 2)$ & $5 \cdot 5$ & $13 / 21 \quad(61.9)$ \\
\hline 3 & 3.4 & $8 / 22 \quad(36.4)$ & $5 \cdot 1$ & $2 / 67 \quad(3.0)$ & $2 \cdot 6$ & $11 / 19 \quad(57.9)$ \\
\hline 4 & $2 \cdot 0$ & $16 / 37 \quad(43 \cdot 2)$ & $2 \cdot 3$ & $5 / 23 \quad(21.7)$ & $1 \cdot 0$ & $7 / 45 \quad(15 \cdot 6)$ \\
\hline 5 & $3 \cdot 3$ & $30 / 41 \quad(73.2)$ & $2 \cdot 3$ & $5 / 22 \quad(22.7)$ & 1.9 & $21 / 43 \quad(48.8)$ \\
\hline 6 & $4 \cdot 5$ & $28 / 80 \quad(35.0)$ & $4 \cdot 3$ & $2 / 40 \quad(5 \cdot 0)$ & 1.6 & $16 / 68 \quad(23.5)$ \\
\hline Overall & - & $113 / 263(43.0)$ & - & $24 / 279(8.6)$ & - & $84 / 234(35.9)$ \\
\hline
\end{tabular}

* Preincubation and test density (original samples $>20 \times 10^{6} / \mathrm{ml}$ with $>40 \%$ motile).

$\dagger$ No. of ova penetrated per total no. of ova (\%).

\section{Variation with respect to fertility}

The data for each subject in Groups 1,2 and 3 are given in Table 5. There was no significant difference between the various parameters of the spermiogram from men in Groups 1 and 2 and the test densities of the preincubated spermatozoa were also similar. Ova inseminated with spermatozoa from men in Group 1 consistently had more than 5 non-motile spermatozoa attached to their vitelline membrane, but this phenomenon only occurred in 4 subjects from Group 2. Apart from one subject, for whom no spermatozoa were seen attached to ova, the other 10 subjects in Group 2 had poor binding of spermatozoa to the vitelline membrane (i.e. 1-5/ovum). Spermatozoa from men in Group 3 consistently had poor binding ability (i.e. none or 1-5 spermatozoa/ovum). After preincubation of spermatozoa from men in Groups 1 and 2, motilities were usually in excess of $80 \%$. However, 4 subjects in Group 3 had samples with $<5 \%$ motile spermatozoa. Each of these patients had zero binding and penetration rates. Three other men in this group also had zero penetration of ova but their post-incubation motilities were better $(10-30 \%)$. In the 2 other subjects, for which the post-incubation motility was reasonable (60 and $50 \%$ ), some positive penetration was achieved ( 7.4 and $6.5 \%$ respectively).

Eight of the samples of spermatozoa from subjects in Group 2 also failed to penetrate ova, but the other 7 subjects showed penetration rates ranging between 1.4 and $8.7 \%$. However, in Group 1 penetration rates ranged between 23.5 and $88.9 \%$ with a geometric mean value of $57.6 \%$. The number of swollen sperm heads or male pronuclei (still with attached tails) per ovum rarely exceeded 5 and was more commonly $1-3$. Occasionally penetration was observed in the extruded second polar body.

When the data from all 39 subjects were combined there was no correlation between the percentage of penetrated ova and the original sperm density, motility or morphology. Of the 476 ova inseminated with spermatozoa from fertile men, 284 were penetrated $(59.7 \%)$ while spermatozoa from the infertile subjects gave a penetration rate of $1.9 \%(11 / 586$ for Group 2) and $1.3 \%(4 / 300$ for Group 3$)$ respectively.

\section{Discussion}

For a spermatozoon to fertilize an ovum it must first traverse the cervical mucus, remain viable while transported in the female tract, and finally penetrate the ovum vestments (cumulus oophorus and zona pellucida) before incorporation into the ooplasm. Clinically the first of these barriers can be examined using a post-coital test (Jaszczak \& Hafez, 1976) or in-vitro tests of sperm penetration in human (Ulstein \& Fjallbrant, 1976) or bovine cervical mucus (Gaddum-Rosse, Blandau \& Lee, 1980). 
Table 5. Penetration of zona-free hamster ova by spermatozoa from fertile and infertile men

\begin{tabular}{|c|c|c|c|c|c|c|}
\hline \multirow{4}{*}{$\begin{array}{c}\text { Subject } \\
\text { No. }\end{array}$} & \multicolumn{4}{|c|}{ Spermatozoa } & & \\
\hline & \multicolumn{2}{|c|}{ In semen sample } & \multicolumn{2}{|c|}{ For insemination } & \multirow{2}{*}{\multicolumn{2}{|c|}{ Gamete interaction }} \\
\hline & Count* & Motility & Count & Motility & & \\
\hline & $\times 10^{6} / \mathrm{ml}$ & (\%) & $\times 10^{6} / \mathrm{ml}$ & (\%) & - Attachment $\dagger$ & Penetration $\Varangle$ \\
\hline \multicolumn{7}{|l|}{ Group I } \\
\hline 1 & 93.5 & 60 & 0.7 & $>80$ & ++ & $9 / 21(43)$ \\
\hline 2 & 60.0 & 40 & 0.8 & $>80$ & ++ & $6 / 24(25)$ \\
\hline 3 & 17.0 & 70 & 1.0 & $>80$ & ++ & $18 / 22(82)$ \\
\hline 4 & 49.5 & 50 & 1.4 & $>80$ & ++ & $18 / 27(67)$ \\
\hline 5 & $57 \cdot 0$ & 50 & 2.5 & $>80$ & ++ & $23 / 44(52)$ \\
\hline 6 & $78 \cdot 0$ & 60 & 2.8 & $>80$ & ++ & $18 / 24(75)$ \\
\hline 7 & 51.5 & 60 & 4.8 & $>80$ & ++ & $24 / 27(89)$ \\
\hline 8 & $38 \cdot 0$ & 70 & $6 \cdot 2$ & $>80$ & ++ & $16 / 19(84)$ \\
\hline 9 & $67 \cdot 0$ & 50 & $7 \cdot 5$ & $>80$ & ++ & $16 / 27(59)$ \\
\hline 10 & 44.0 & 60 & $7 \cdot 7$ & $>80$ & ++ & $15 / 30(50)$ \\
\hline 11 & 92.5 & 70 & 9.0 & $>80$ & ++ & $14 / 21(67)$ \\
\hline 12 & $82 \cdot 0$ & 70 & $9 \cdot 5$ & $>80$ & ++ & $32 / 47(68)$ \\
\hline 13 & $72 \cdot 0$ & 65 & 9.9 & $>80$ & ++ & $31 / 42(74)$ \\
\hline 14 & $235 \cdot 0$ & 80 & 11.8 & $>80$ & ++ & $12 / 51(24)$ \\
\hline 15 & 77.5 & 70 & $12 \cdot 0$ & $>80$ & ++ & $32 / 50(64)$ \\
\hline \multicolumn{7}{|l|}{ Group 2} \\
\hline 1 & $67 \cdot 0$ & 70 & $3 \cdot 2$ & $>80$ & + & $0 / 52(0)$ \\
\hline 2 & 245.0 & 70 & $4 \cdot 6$ & $>80$ & + & $2 / 32(6)$ \\
\hline 3 & 137.0 & 80 & $4 \cdot 6$ & $>80$ & + & $0 / 29(0)$ \\
\hline 4 & 183.5 & 90 & $4 \cdot 8$ & $>80$ & + & $1 / 27(4)$ \\
\hline 5 & $75 \cdot 0$ & 60 & 5.0 & 70 & + & $0 / 45(0)$ \\
\hline 6 & $28 \cdot 0$ & 60 & $5 \cdot 0$ & 60 & + & $0 / 46(0)$ \\
\hline 7 & $50 \cdot 0$ & 40 & $5 \cdot 0$ & 50 & + & $1 / 70(1)$ \\
\hline 8 & $72 \cdot 0$ & 70 & $5 \cdot 0$ & $>80$ & + & $0 / 42(0)$ \\
\hline 9 & $120 \cdot 0$ & 70 & $5 \cdot 3$ & $>80$ & $+/++$ & $2 / 70(3)$ \\
\hline 10 & $30 \cdot 0$ & 60 & $6 \cdot 0$ & $>80$ & ++ & $1 / 29(3)$ \\
\hline 11 & 97.0 & 60 & $6 \cdot 0$ & 50 & 0 & $0 / 27(0)$ \\
\hline 12 & $23 \cdot 0$ & 70 & $6 \cdot 5$ & $>80$ & ++ & $2 / 30(7)$ \\
\hline 13 & $48 \cdot 0$ & 55 & $7 \cdot 5$ & 70 & + & $2 / 23(9)$ \\
\hline 14 & $73 \cdot 5$ & 70 & 9.4 & $>80$ & + & $0 / 47(0)$ \\
\hline 15 & $71 \cdot 5$ & 60 & 9.5 & $>80$ & $+1++$ & $0 / 16(0)$ \\
\hline \multicolumn{7}{|l|}{ Group 3} \\
\hline 1 & 14.5 & 70 & 1.0 & 60 & $+/++$ & $2 / 27(7)$ \\
\hline 2 & 1.5 & 10 & 1.0 & $<5$ & 0 & $0 / 31(0)$ \\
\hline 3 & 8.0 & 40 & 1.0 & $<5$ & 0 & $0 / 35(0)$ \\
\hline 4 & 7.5 & 70 & 1.0 & $<5$ & 0 & $0 / 32(0)$ \\
\hline 5 & $29 \cdot 0$ & 10 & $1 \cdot 1$ & $<5$ & 0 & $0 / 34(0)$ \\
\hline 6 & $10 \cdot 0$ & 40 & $6 \cdot 0$ & 25 & $0 /+$ & $0 / 32(0)$ \\
\hline 7 & $8 \cdot 5$ & 70 & $8 \cdot 0$ & 30 & 0 & $0 / 33(0)$ \\
\hline 8 & $9 \cdot 0$ & 70 & 9.0 & 50 & + & $2 / 31(7)$ \\
\hline 9 & $40 \cdot 0$ & 20 & 11.0 & 10 & $0 /+$ & $0 / 45(0)$ \\
\hline
\end{tabular}

* $>60 \%$ with normal morphology.

$\dagger 0$, no attachment;,$+ 1-5$ spermatozoa attached;,$++>5$ spermatozoa attached.

$\ddagger$ No. of ova penetrated per total no. of ova tested (\%).

The penetration of cumulus cells and the zona pellucida can only be tested using human material and this is not likely to be routinely possible with freshly ovulated ova. However, Overstreet \& Hembree (1976) have successfully used immature human oocytes collected from follicles of cadavers, and shown a relationship between the ability of spermatozoa to penetrate the zona pellucida and the subjects' fertility. This in-vitro assay has also been examined in 
conjunction with a zona-free hamster ovum penetration test (Overstreet et al., 1980), thus permitting evaluation of most stages of sperm-ovum interaction. The preparation of spermatozoa for this test also examines the ability of the spermatozoa to remain viable with time and undergo the changes associated with capacitation that normally occur in the female tract.

The major practical problem of establishing a heterologous gamete penetration test for routine clinical use is of timing the collection of ova to coincide with the preparation of spermatozoa. This led to our use of immature animals because they could be induced to superovulate without reference to the stage of the oestrous cycle and the penetration rate by human spermatozoa was similar to ova from adult animals. The acquirement of mature ova by spontaneous in-vitro maturation of dictyate oocytes from antral follicles was not feasible because recovery of usable oocytes was low. Media other than BWW can be used, e.g. Haidri \& Gwatkin (1973) obtained $>90 \%$ polar body formation with a different chemically defined medium (see Table 1), but the number of ova per animal does not match recovery after induction of superovulation.

Delivery of semen samples provides the second controlling factor. Human spermatozoa are capable of penetrating human ova or denuded zona-free hamster ova after 4-8 h incubation (see review by Rogers, 1978). If samples are delivered at $09: 00 \mathrm{~h}$ (the time preferred by the majority of patients requested to supply semen for analysis), penetrated ova are not scored until later that evening. The method recommended by Rogers (1978) is to prepare the spermatozoa one afternoon, preincubate overnight and run the penetration test the following day. This allows one person to perform the test during normal working hours but imposes limitations on the method if semen samples are delivered $24 \mathrm{~h}$ before testing. The results from the present work suggest that spermatozoa do remain viable over $24-30 \mathrm{~h}$, but that a 42 -h incubation leads to erroneous results with poor binding of spermatozoa to the ova and subsequent reduced penetration rates (Table 3). Furthermore, the incidence of specific agglutination between spermatozoa increases substantially, suggesting changes in the sperm head surfaces. The viable life of spermatozoa in vivo is not known precisely but Hafez (1978) quotes approximately $25 \mathrm{~h}$ which corresponds with our results.

A way around the problem of providing a sample when ova are available is to freeze the semen in liquid nitrogen until appropriate, although there are as yet no reports in the literature regarding changes in penetration rates of spermatozoa before and after freezing. The corollary of this is to freeze and store the ova or use salt-stored eggs (Yanagimachi et al., 1979). This would make the test available to laboratories without access to hamsters (e.g. Australia).

The methods of centrifugation and resuspension, and concentration after layering both proved acceptable for removing spermatozoa from the seminal plasma, but the layering method recovers predominantly motile spermatozoa and excludes cellular debris and dead and non-motile spermatozoa, much as the cervix does in vivo. Theoretically, therefore, the population of spermatozoa recovered would match that most likely to reach the site of fertilization in vivo. However, while this method is generally acceptable to most specimens, samples that have high viscosities, or have low values for sperm density, volume and/or motility, have to be prepared by centrifugation and resuspension to provide enough spermatozoa for testing. Recovery of motile spermatozoa by layering is not related to the original count or motility of the sample, but is probably best correlated with sperm velocity or the surface area between the two layers.

One of the unexpected findings of this study was the difference in penetration rates for samples preincubated overnight in air or an atmosphere of $5 \% \mathrm{CO}_{2}$. Both binding to the vitelline membrane and penetration of ova were significantly reduced if preincubation was carried out in the $\mathrm{CO}_{2}$ incubator. This was all the more unexpected since those laboratories using a short incubation time (i.e. about $8 \mathrm{~h}$ ) leave the spermatozoa in a $\mathrm{CO}_{2}$ incubator (E. Rudak, personal communication), and Yanagimachi et al. (1976) observed no difference in penetration rates after $7 \mathrm{~h}$ in either gas phase. Further experiments will be needed to define this discrepancy.

Another important factor in the successful application of this bioassay is the effect of the 
density of spermatozoa in the test droplet. It is known that capacitation does not readily occur if traces of seminal plasma are present (Kanwar, Yanagimachi \& Lopata, 1979) or if sperm densities are too high (Rogers, 1978). This is demonstrated in Text-fig. 1 by one subject for which there was no penetration at a density of $18 \times 10^{6} / \mathrm{ml}$ but acceptable positive results at lower densities of $1-9 \times 10^{6} / \mathrm{ml}$. Perhaps high concentrations of acrosin associated with the high sperm densities inhibited penetration (Gwatkin, Wudl, Hartree \& Fink, 1977). It is difficult to draw firm conclusions from the other data about possible effects over the range $1-9 \times 10^{6} / \mathrm{ml}$, notwithstanding the 857 ova examined, but there would seem to be a tendency to decreasing penetration rates with decreasing sperm densities. (The data of Overstreet et al. (1980: Table 4) also show a similar reduction in penetration rate with sperm concentrations $<1 \times 10^{6} / \mathrm{ml}$.) This is not unreasonable because a finite number of motile spermatozoa are needed to permit enough 'direct hits' on an ovum for penetration to occur. This perhaps argues for the use of a constant number of motile spermatozoa in the test droplet for all semen samples tested. However, this is not always practical or advisable for a test of fertility combining many aspects of the processes that spermatozoa undergo before fertilization in vivo (i.e. removal from seminal plasma, dilution and survival with time). Furthermore, the densities used in the test droplets are still in excess of those found at the site of fertilization in women (Hafez, 1978).

As well as the variation in penetration rates noted above, the intra-subject variation (with similar insemination densities) can be large. Subject $\mathbf{A}$ had one test result which would be classified as negative (i.e. $<10 \%$ penetration) while the other 5 were positive $(; ? .5 \%$ ), and similarly Subject B had two inconclusive results (10-25\% penetration) while the o. ers were negative. Other reports have not quoted intra-subject variation, with the exception of duplicates (Rogers et al., 1979), so more data on this aspect of the test are required. Nevertheless, the overall results for each of the 3 subjects were conclusive.

Replicate groups of ova in different droplets of spermatozoa from the same sample gave essentially similar results. Obviously there are many factors contributing to the penetration rate, but it is doubtful whether differences between animals or groups of prepared ova affected the results because their selection after several washes was random.

To date Rogers et al. (1979), Hall et al. (1980) and Overstreet et al. (1980) have shown that capacitated spermatozoa from fertile men are capable of penetrating zona-free hamster ova at a high rate $(>25 \%)$ while those from infertile men rarely exceed $10 \%$ penetration. Furthermore, penetration rates are not related to the original density, motility or morphology of the spermatozoa. The results of the present study support and extend these observations. Furthermore, the careful selection of men with respect to proven conception, and the exclusion of the wife as the infertile partner, demonstrates the validity of the bioassay.

When the data from the two groups of infertile men were compared it was clear that prepared spermatozoa from subjects in Group 3 had a poorer chance of penetrating zona-free ova. Firstly, the samples for insemination usually had a low density of motile spermatozoa with many of the specimens showing a marked decline in motility after the overnight incubation which is necessary for capacitation. This in itself could be a useful diagnostic test because high penetration rates of ova are associated with samples of good motility ( $>80 \%)$ and active forward progression. Secondly, the demonstration that there was a decline in penetration rate if the density of motile spermatozoa in the insemination droplet was less than $1 \times 10^{6} / \mathrm{ml}$ suggests that the application of this bioassay to semen samples with a poor spermiogram merely confirms the original diagnosis of subfertility. However, in those men who have normal spermiograms but are still infertile, the bioassay is of value for recognizing those with a dysfunction at the level of sperm survival, binding to, and penetration of the ooplasm. The fortuitous selection of men in Group 2 demonstrates these pathologies since the densities and motilities of tested spermatozoa were not significantly different from those of subjects with proven fertility (Group 1), while the binding and penetration of ova was severely reduced. The management of patients who persistently obtain negative results in a heterologous ovum penetration test still remains 
difficult and at present artificial insemination by donor is probably the only treatment for the couple.

In conclusion the results of this study have demonstrated that immature hamsters provide a convenient means of obtaining ova for study and the preparation of semen samples by layering provides viable, motile spermatozoa for insemination up to $24 \mathrm{~h}$ later if the incubation associated with capacitation is carried out at $37^{\circ} \mathrm{C}$ in air. The heterologous gamete penetration test has a useful role as an additional assessment characteristic to the classic spermiogram, but its routine use is best reserved for selected cases of unexplained infertility. The assay does, however, have a potential value for monitoring drug therapy, testing new methods of male contraception, and screening AID donors of unproven fertility.

\section{References}

Barros, C., Gonzalez, J., Herrera, E. \& Bustos-Obregon, E. (1978) Fertilizing capacity of human spermatozoa evaluated by actual penetration of foreign eggs. Contraception 17, 87-92.

Barros, C., Gonzalez, J., Herrera, E. \& Bustos-Obregon, E. (1979) Human sperm penetration into zona-free hamster oocytes as a test to evaluate the sperm fertilizing ability. Andrologia 11, 197-210.

Biggers, J.D., Whitten, W.K. \& Whittingham, D.G. (1971) The culture of mouse embryos in vitro. In Methods in Mammalian Embryology, 1st edn, pp. 86-116. Ed. J. C. Daniel, Jr. W. H. Freeman \& Co., San Francisco.

Eliasson, R. (1976) Semen analysis and laboratory workup. In Male Fertility, pp. 169-188. Eds A. T. K. Cockett \& R. L. Urry. Grune \& Stratton, New York.

Gaddum-Rosse, P., Blandau, R.J. \& Lee, W.I. (1980) Sperm penetration into cervical mucus in vitro. II. Human spermatozoa in bovine mucus. Fert. Steril. 33, 644-648.

Gwatkin, R.B.L., Wudl, L., Hartree, F.F. \& Fink, E. (1977) Prevention of fertilization by exposure of hamster eggs to soluble acrosin. J. Reprod. Fert. $\mathbf{5 0}$, 359-361.

Hafez, E.S.E. (1978) Transport and survival of spermatozoa in the human female reproductive tract. In Human Fertilization, pp. 119-127. Eds H. Ludwig \& P. F. Tauber. G. Thieme, Stuttgart.

Haidri, A.A. \& Gwatkin, R.B.L. (1973) Requirements for the maturation of hamster oocytes from preovulatory follicles. J. Reprod. Fert. 35, 173-176.

Hall, J.L., Sloane, C.S. \& Hammond, M.G. (1980) Correlation of heterologous in vitro fertilization using human sperm and hamster ova with clinical evaluation of male infertility. Fert. Steril. 33, 238, Abstr.

Hanada, A. \& Chang, M.C. (1972) Penetration of zona-free eggs by spermatozoa of different species. Biol. Reprod. 6, 300-309.

Iwamatsu, T. \& Chang, M.C. (1972) Sperm penetration in vitro of mouse oocytes at various times during maturation. J. Reprod. Fert. 31, 237-247.

Jaszczak, S. \& Hafez, E.S.E. (1976) Postcoital test. In Human Semen and Fertility Regulation in Men, pp. 375-382. Ed. E. S. E. Hafez. C. V. Mosby \& Co., St Louis.
Kanwar, K.C., Yanagimachi, R. \& Lopata A. (1979) Effects of human seminal plasma on fertilizing capacity of human spermatozoa. Fert. Steril. 31, 321-327.

Lopata, A., Brown, J.B., Leeton, J.F., McTalbot, J. \& Wood C. (1978) In vitro fertilization of preovulatory oocytes and embryo transfer in infertile patients treated with clomiphene and human chorionic gonadotrophin. Fert. Steril. 30, 27-35.

Overstreet, J.W. \& Hembree, W.D. (1976) Penetration of the zona pellucida of non-living human oocytes by human spermatozoa in vitro. Fert. Steril. 27, $815-831$.

Overstreet, J.W., Yanagimachi, R., Katz, D.F., Hajashi, K. \& Hanson, F.W. (1980) Penetration of human spermatozoa into the human zona pellucida and the zona-free hamster egg. A study of fertile donors and infertile patients. Fert. Steril. 33, 534-542.

Rogers, B.J., Van Campen, H., Ueno, M., Lambert, H., Bronson, R. \& Hale, R. (1979) Analysis of human spermatozoal fertilizing ability using zona-free ova. Fert. Steril. 32, 664-670.

Rogers, J.R. (1978) Mammalian sperm capacitation and fertilization in vitro. A critique of methodology. Gamete Res. 1, 165-223.

Steptoe, P.C. \& Edwards, R.G. (1978) Birth after the reimplantation of a human embryo. Lancet, p. 366.

Ulstein M. \& Fjallbrant, B. (1976) In vitro tests of sperm penetration in cervical mucus. In Human Semen and Fertility Regulation in Men, pp. 383-388. Ed. E. S. E. Hafez. C. V. Mosby \& Co., St Louis.

Van Zyl, J.A., Menkveld, R., Retif, A.E. \& Niekirk, W.A. (1976) Oligozoospermia. In Human Semen and Fertility Regulation in Men, pp. 363-369. Ed. E. S. E. Hafez. C. V. Mosby \& Co., St Louis.

Yanagimachi, R., Yanagimachi, H. \& Rogers, B.J. (1976) The use of zona-free animal ova as a test system for the assessment of the fertilizing capacity of human spermatozoa. Biol. Reprod. 15, 471-476.

Yanagimachi, R., Lopata, A., Odom, C.B., Bronson, R.A., Mahi, C.A. \& Nicholson, G.L. (1979) Retention of biologic characteristics of zona pellucida in highly concentrated salt solution: the use of salt stored eggs for assessing the fertilizing capacity of spermatozoa. Fert. Steril. 31, 562-574. 